\title{
1 NTONIO DE TEJEDA Y ANTÓN SÁNCHEZ, PINTORES: UNA DECORACIÓN EN DOS TIEMPOS PARA LA CAPILLA DE LAS DONCELLAS DE LA CATEDRAL DE SEVILLA
}

ELENA ESCUREDO BARRADO

Universidad de Sevilla escuredo@us.es

\begin{abstract}
Resumen: La capilla de la Anunciación de la Catedral de Sevilla, sede de la Hermandad de las Doncellas, fue fundada por Micer García de Gibraleón en el primer tercio del siglo XVI. A lo largo de la centuria se llevaron a cabo diversas empresas para adecentar y ornamentar el espacio, desde el encargo del retablo que la presidía hasta las rejas que la cerraban. Las pesquisas en el Archivo de Protocolos Notariales de la capital hispalense, han permitido sacar a la luz nuevos documentos que permiten imaginar cómo lucía aquella esquinada capilla del magno templo metropolitano: por un lado, la decoración mural de la pared frontera al retablo, obra de Antonio de Tejeda; y por otra, la policromía de la reja lateral y la pintura del paramento que la acogía, encargo aceptado por Antón Sánchez.
\end{abstract}

Palabras clave: Doncellas / pintura / siglo XVI / Sevilla / Antonio de Tejeda / Antón Sánchez.

Summary: The chapel of the Annunciation, in the Cathedral of Seville, was the headquarters of the Brotherhood of the Maidens, founded by Micer García de Gibraleón in the first third of the sixteenth century. Throughout the century, several undertakings were carried out to tidy up and decorate the space, from the commission of the altarpiece to the fences, which closed it. The researches in the Protocols Archive of Seville have revealed new documents that allow us to imagine how this chapel looked like originally: on the one hand, the mural decoration of the wall in front of the altarpiece, Antonio de Tejeda's work; and on the other hand, the polychrome of the lateral fence and the painting of the wall that accommodated it, a commission accepted by Antón Sánchez.

Key words: Maiden / painting / XVI century / Seville / Antonio de Tejeda / Antón Sánchez.

Las últimas y recientes investigaciones llevadas a cabo por distintos historiadores acerca de la capilla de las Doncellas de la catedral de Sevilla y sobre su fundador Micer García de Gibraleón han permitido desvelar los entresijos históricos de su fundación, así como la contratación de las diversas obras artísticas que para su ornamentación se encargaron. Sin embargo, los hallazgos en el Archivo de Protocolos Notariales de la ciudad hispalense permiten seguir conociendo las diferentes intervenciones que se llevaron a cabo en el siglo XVI, llamadas a adecentar, mejorar y completar la fisonomía de una capilla que debía ser santo y se- ña de su promotor y de la Hermandad a la que servía de sede.

El 27 de febrero de 1517, el Cabildo de la Catedral de Sevilla concedía a Micer García de Gibraleón una capilla en la nave de San Sebastián, vecina a la puerta de la Concepción. Estaría dedicada a la Anunciación de Nuestra Señora, y destinada al enterramiento de aquel y sus sobrinos. ${ }^{1}$ Tradicional y popularmente, se le conoce como la "Capilla de las Doncellas", distintivo que vino determinado por ser sede de una Hermandad cuya misión principal era otorgar dotes a las doncellas que carecieran de medios económicos que aportar al matri-

\footnotetext{
* Fecha de recepción: 15 de abril de 2017 / Fecha de aceptación: 14 de julio de 2017.

1 La figura de este protonotario, escribano apostólico y agente del Cabildo en la corte romana ha sido bien estudiada por OLLERO PINA, Juan Antonio, 2016, pp. 355-384.
} 


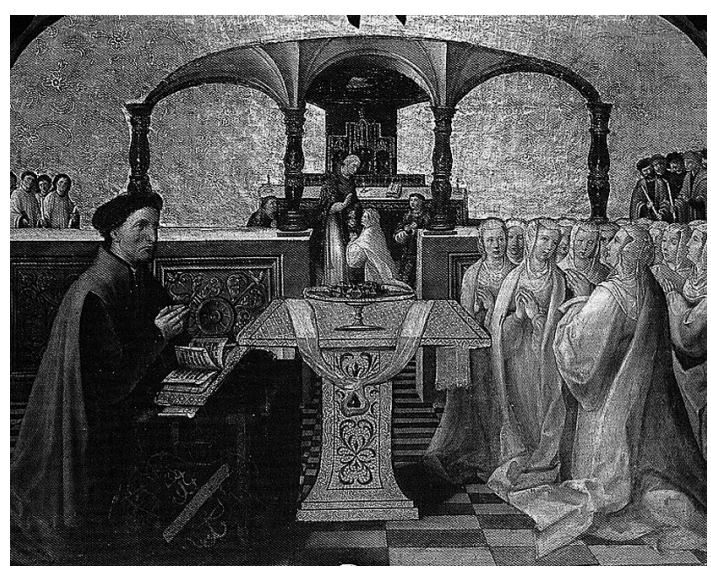

Fig. 1. La entrega de dote de las doncellas. Cristóbal de Morales, h. 1534. Capilla de las Doncellas, Catedral de Sevilla.

monio, la cual había sido fundada por el propio García de Gibraleón en 1521, gracias a la bula fundacional expedida por León $X$ cuatro años antes. ${ }^{2}$ Desde el momento de su fundación, la hermandad realizó una serie de encargos con los que mejorar el aspecto de la capilla, siendo en los años cincuenta cuando se acometen las obras de mayor calado, con el fin de dotar al espacio de una impresión visual acorde a la importancia de la hermandad que albergaba.

A pesar de que no existe documento contractual que lo cerciore, el retablo mayor debió ser encargado al pintor Cristóbal de Cárdenas, como bien atribuyó Post y ratificó el profesor Serrera. ${ }^{3}$ Actualmente, el interesante conjunto de tablas se encuentra inserto en una estructura lígnea barroca fechable en 1771. El retablo original debió asentarse hacia 1534, momento en que también se colocó la gran vidriera de Arnao de Vergara que ilumina el interior de la capilla y que se relaciona temáticamente con la advocación de la misma. Del banco del retablo, donde también debieron figurar los cuatro padres de la iglesia, se ha conservado una escena de gran valor histórico y documental: la Entrega de dote de las doncellas, donde se incluye un retrato del fundador [Fig. 1]. Éste preside la entrega de las doncellas, las cuales aparecen de blanco y sin adornos, como exigían

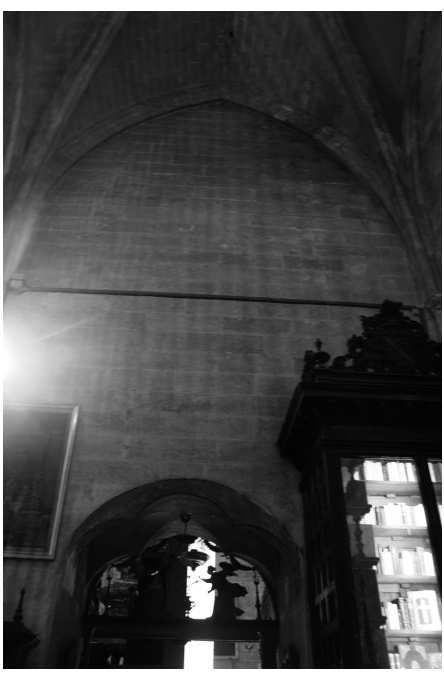

Fig. 2. Pared frontera al altar mayor. Capilla de las Doncellas. Catedral de Sevilla.

los estatutos. Frente a ellas, una de las "dueñas honradas", nombre con el que se denominaban a las mujeres que debían acompañar a las jóvenes casaderas. Las bolsas de dinero destinadas a la dote descansan sobre la mesa, la cual articula y centra la composición. En el fondo, pueden apreciarse dos grupos de hermanos a través de los cuales se representan a los 600 matrimonios que integraban la Hermandad. ${ }^{4}$ Por su parte, el centro del retablo está presidido por un grupo escultórico de la Anunciación, obra barroca posterior a la cronología de las tablas, el cual se flanquea, en dos niveles, por las tablas de Santo Tomás y Santiago el menor, en el lado derecho, y San Bartolomé y San Pedro, en el izquierdo. El conjunto se remata por un Calvario, conservado del retablo original.

Al tiempo que el retablo había sido asentado, el propio García de Gibraleón convenía con el pintor Antonio de Tejeda la pintura de "la pared que esta frontero al altar mayor de la dicha capilla hasta donde esta encalada la dicha pared" ${ }^{5}$ Puesto que la capilla estaba destinada a ser lugar de enterramiento del comitente y sus sobrinos, la temática de la decoración en cuestión no podía ser otra que un Juicio Final [Fig. 2]. El documento notarial es parco en detalles, pues no especifica el tamaño

2 ORTIZ DE ZÚÑIGA, Diego, 1677, p. 434. Sobre la fundación de la Hermandad y su finalidad, ver GIL, Juan, 2000, pp. 37-50.

${ }^{3}$ Fue un artista descubierto por Gestoso, quien le dedicó un artículo en fecha muy temprana GESTOSO, José, 1900, pp. 386390. Sobre la primera y aceptada atribución ver en POST, Chandler R., 1950, pp. 176-179. Aparece también brevemente citado en VALDIVIESO, Enrique, 2002, p. 66

${ }^{4}$ Fue encargado a José Rivera quien, tras acuerdo con el cabildo, debía integrar en él solo "las pinturas de antiguo que estuvieran servibles y menos maltratadas". SERRERA CONTRERAS, Juan Miguel, 1984, pp. 383-384.

${ }^{5}$ Archivo Histórico de la Provincia de Sevilla, sección de Protocolos Notariales (AHPSPN), legajo 46, registro 8, sin foliar. 
ni la técnica a emplear. No obstante, dispone que "todo el oro que fuere menester para la dicha obra sea a costa de vos el dicho beneficiado Garcia de Gibraleon", lo que lleva a pensar en una pintura donde las reminiscencias góticas estarían presentes en forma de detalles dorados, a la manera que también Cristóbal de Morales había dispuesto en sus tablas para el retablo. El precio estipulado fue de veinte mil maravedíes, los cuales serían pagados en tres partes, como solía ser habitual, y dos cahíces de trigo, que se entregarían al pintor en el mes de agosto, coincidiendo con el día de Nuestra Señora. Actualmente, nada resta de aquella pintura que debió otorgar una gran riqueza visual a una capilla cuya luz quedaba tamizada por la colorida vidriera, donde la semántica de la vía anagógica quedaba codificada en una sintaxis de temprano clasicismo [Fig. 3].

Son pocos los datos que se tienen de este pintor, quien debió desarrollar su actividad artística en el segundo cuarto del siglo XVI. Se desconoce con qué maestro se pudo formar, pero teniendo en cuenta la indiscutible influencia que tuvo Alejo Fernández para la pintura sevillana de principios de siglo, su arte debió ser deudor del de aquel. Su aparición en las fuentes documentales es abundante en la década de los treinta. Un año antes de acometer el encargo referido, Baltasar del Río, obispo de Scalas, le encomendó la decoración pictórica de su capilla, también en el templo metropolitano. El pintor se comprometió a hacer ocho figuras, a seis ducados cada una: los cuatro evangelistas y cuatro alegorías de los dolores. ${ }^{6}$ Fue quizá su buen quehacer en esta decoración, hoy desaparecida, la que le valió la asignación por parte de la hermandad de las Doncellas, pues tuvieron un modelo cercano donde admirar las cualidades plásticas del pintor, convenciéndose de que era su talento digno de merecer tal encargo.

Su labor profesional no se limitó a la pintura mural, pues en 1535 recibiría un encargo para realizar un retablo, destinado a la capilla de Francisco Pavón, maestre difunto. La tabla central albergaba un "crucificado en la cruz solo con sus lejos y el cielo", y se flanqueaba de cuatro tablas laterales, dos a la derecha con la imagen de Nuestra Señora, arriba, y San José, abajo; y a la izquierda, un San Gabriel y un San Telmo. ${ }^{7}$ Ninguna de estas obras ha llegado hasta nosotros, y las fuentes primarias apenas han arrojado más datos de su currí-

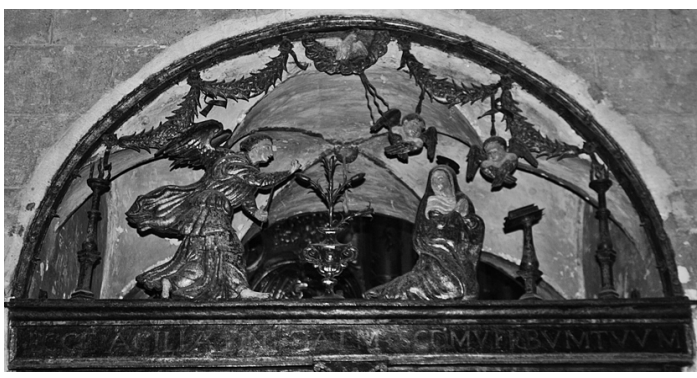

Fig. 3. Anunciación. Pedro Varela (diseño y fundición) y Antón Sánchez (policromía), 1551-1553. Capilla de las Doncellas, Catedral de Sevilla.

culum artístico, por lo que, a la espera de nuevos hallazgos y atribuciones, se trata de un pintor que engrosa, desde un olvido injusto, la lista de artistas sevillanos ignorados por la historiografía a causa de que no son más que recuerdos notariales empolvados. El artista entregó testamento el 7 de julio de 1536, por lo que su trayectoria artística y vital no se debió de extender mucho más allá. ${ }^{8}$ Pidió ser sepultado en la iglesia de San Juan de la Palma, aunque era parroquiano de la iglesia de la Magdalena, a la que manda un real de plata por "reverencia de los santos sacramentos que de ella he recibido". Asimismo, el documento revela cuáles fueron sus últimos trabajos, así como las deudas contraídas y los maravedíes que les deben por trabajos realizados o en proceso de ejecución, entre ellos un retablo para el pueblo de La Campana, otro para la villa de Palos de la Frontera o una viga de imaginería para la iglesia del Salvador de la capital hispalense.

Los trabajos de adecentamiento de la capilla se intensificaron a mediados de la centuria y es entonces cuando las reformas afectan al retablo, cuya guarnición será pintada y dorada por los artistas Andrés Morín y Antón Rodríguez. También la bóveda de la capilla será arreglada por el albañil Diego Torres y se acometerá la realización de un retablo para la sacristía que corrió a cargo de Juan Pérez. Es también ahora cuando las arcaicas rejas de madera se sustituyen por otras de hierro, más acorde a los nuevos tiempos y al valor implícito de la capilla y la hermandad a la que daba cobijo. Aunque desde 1548 existían modelos y dibujos para la realización de la reja chica, la cual cerraba el acceso lateral, será en 1551 cuando Hernán Suárez, secretario de la capilla, haga pacto y

\footnotetext{
${ }^{6}$ Contrato publicado por HERNÁNDEZ DÍAZ, José, 1933, p. 98.

7 Ibidem.

${ }^{8}$ AHPSPN, legajo 9794, registro 6, f. 135 y ss. [Ver Apéndice documental].
} 


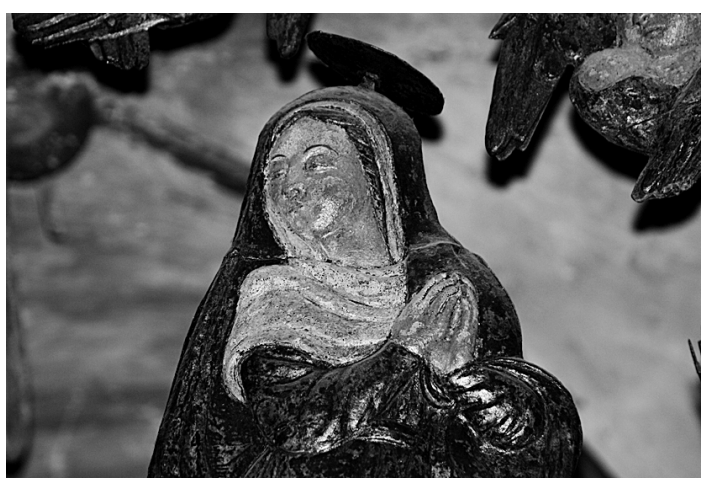

Fig. 4. Anunciación (detalle). Pedro Varela (diseño y fundición) y Antón Sánchez (policromía), 1551-1553. Capilla de las Doncellas, Catedral de Sevilla.

postura con el rejero Pedro Varela. ${ }^{9}$ El propio artista dio un diseño para la reja, que terminaría siendo modificado a petición de la hermandad antes de la firma del contrato. El formato de la reja y su decoración se adaptan perfectamente al arco que debían cerrar, por lo que los dos batientes de barrotes torsos se coronan por una decoración en medio punto con la escena de la Anunciación, realizada en dos haces. Debía ir totalmente estañada, a excepción de las partes reservadas a la pintura y al dorado, labores que se encargaron al pintor Antón Sánchez.

Aunque el nombre de este artista ya fue desvelado por Inmaculada Ríos, el hallazgo del contrato notarial, entregado en 1553, permite conocer las condiciones estipuladas: el pintor Antón Sanchez, vecino de la collación del Salvador, es "convenido e conçertado con vos los señores priores conçiliarios de la Capilla de las Doncellas e con el arcediano de Ribadesil e con el liçençiado Gonzalo Suarez de Leon, priores de la dicha capilla, en su nombre, que estan presentes, en esta manera que yo me obligo de dorar e pintar una reja que esta en la dicha capilla de las doncellas en la puerta chica". ${ }^{10}$ La factura de esta obra había salido a concurso público, siendo adjudicada a la baja al mejor postor. El pintor se ofreció a darla terminada en toda perfección por dieciocho ducados, por lo que resultó su oferta la más asequible de cuan- tas se presentaron. Habiendo leído las condiciones, fueron muchos los artistas que se interesaron por su ejecución. Sin embargo, las cantidades propuestas resultaron demasiado gravosas.

Siendo testigos los escribanos Miguel Jerónimo de León y Antón Pérez, la obra quedo adjudicada a Antón Sánchez, quien puso como fiador al también pintor Pedro Villegas, y se comprometió a hacerla, aceptando cobrarla en dos pagos, uno de nueve ducados en reales de plata, al comenzar la obra, y los nueve restantes una vez finalizada. La última cláusula es curiosa, aunque usual en la época, y en ella el pintor "que esta obra tomare se ha de obligar a pagar al maestro que hizo las dichas condiçiones un ducado e a los maestros que se juntaren al remate, otro ducado, e ha de obligarse a pagar al escribano e ha de obligarse a dar fyança abonada, que es a contento de sus mercedes e si alguna cosa de menos quedare por poner en estas condiçiones que sea necesaria a la dicha obra que sea obligado de lo facer sin pedir otra demasia ni alegar otro derecho niguno".

Los trabajos de policromía y dorado debían abarcar tanto la cara externa como interna de la reja, siendo la escena de la Anunciación la que recibió todas las atenciones y cuidados [Fig. 3]. El medio punto superior incluía las figuras del arcángel Gabriel, a la izquierda, y la Virgen María, a la derecha, como fue habitual antes de que el Concilio de Trento invirtiera el orden de los factores, sin alterar el producto. Flanqueándolos en la parte exterior, dos flameros llameantes, y en la parte superior, la paloma como símbolo del Espíritu Santo. La Virgen, arrodillada frente a un atril, se vuelve ante la irrupción de la figura angelical, al tiempo que dos serafines revolotean por encima de su cabeza [Fig. 4]. ${ }^{11} \mathrm{El}$ implacable paso del tiempo, con sus correspondientes factores climatológicos, ha legado al momento presente una reja casi desnuda de su corteza al óleo, pues apenas se conserva parte de la encarnadura en el rostro del ángel y la Virgen, así como ciertas notas de color, muy desvaído, en los ropajes de ambos personajes. Al término de las labores de Antón Sánchez, la obra debía lucir con primor, pues el estaño había queda-

\footnotetext{
9 La reja chica de la capilla de las Doncellas ha sido bien documentada y estudiada recientemente por RíOS COLLANTES DE TERÁN, Inmaculada, 2013, pp. 415-440.

10 Inmaculada Collantes ya lo recogió en su artículo arriba citado, según extrajo de los documentos encontrados en el Fondo de la Hermandad de las Doncellas del Archivo de la Catedral de Sevilla. No obstante, aquí se presenta el documento donde se registran las condiciones del encargo, hallado en AHPSPN, oficio 16, legajo 9836, f. 159 y ss. [Ver Apéndice documental].

${ }^{11}$ Estos serafines no existían cuando la reja fue entregada en 1551, pues resultan de un encargo realizado dos años más tarde por el tesorero Antón Manuel al propio Pedro de Varela, y por los que pagó 1.145 maravedíes. Nota incluida en RíOS COLLANTES DE TERÁN, Inmaculada, 2013, p. 419.
} 
do velado por unos colores vivos, unas encarnaduras cuidadas y unos sutiles detalles dorados llamados a dignificar y exaltar la escena allí descrita. Para la Virgen se pensó en un manto púrpura con motivos en azul, mientras que la saya carmín debía llevar brocados de oro a modo de cenefa en su parte inferior. Los cabellos y la diadema que la corona debían ir en dorado, al igual que los del ángel, cuya diadema, cetro y rótulo también irían en oro. La dalmática de Gabriel sería de brocado verde y la capa, carmín; sus alas, doradas por ambas partes, dejando las plumas en verde y azul [Fig. 5]. Sobre el dintel, el rótulo AVE MARÍA PURISIMA debía ser escrito con letras aúreas. Ni siquiera los detalles más pequeños se dejaron al azar, pues se pensó que aunque las azucenas fueran doradas, las hojas debían ser verdes y las flores carmín; el atril sería dorado, igual que el canto del libro de rezos cuyas hojas pintaría de blanco para poder insertar letras escritas en ellas. Los candeleros de los lados presentarían un soporte dorado, mientras que las llamas serían color rojo. El arco, en cuya clave se encontraba la nube que cobijaba la paloma del Espíritu Santo, estaría dorado, igual que los cuatro festones que de él colgaban, aunque sus rosas debían ser policromadas en rojo, sus hojas en verde y sus frutos en rosa. Los serafines que revolotean sobre María también debían tener los cabellos dorados y las alas sacadas de carmín o verde, a gusto del pintor.

La minuciosidad en la descripción de cada una de las condiciones permite imaginar con todo lujo de detalles cuál debió ser su aspecto una vez acabadas las labores de Antón Sánchez. Aunque en el contrato no se especifica el tiempo disponible para la realización de dicho encargo, el artista debió tardar algo más un mes en policromar la reja, pues en julio de ese mismo año se le adjudicaba, de nuevo en una subasta a la baja, otro cometido por la cual debía pintar "la portada de la capilla de las Doncellas adonde se puso la rexa nueva, la cual mandaron hacer los magestuosos priores e conçiliares de la dicha capilla". En este caso se trataba de una pintura mural que otorgara valores decorativos, no sólo al paramento donde se situaba la entrada lateral sino también a la bóveda de la entrada cerrada por aquella reja chica que tan vistosamente había policromado. Atendiendo a las condiciones, es preciso pensar que en ese momento la reja no estaba todavía asentada, aunque sí debía estar terminada en el taller del pintor. El documento es minucioso en detalles, aunque la trabada descripción dificulta su claro entendimiento. Una lectura atenta y analítica permite revivir cómo debió ser aquel esquinado lugar de la

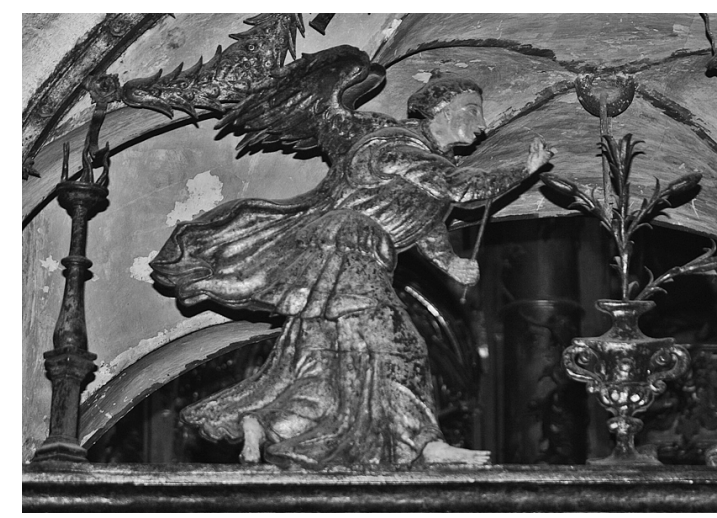

Fig. 5. Anunciación (detalle). Pedro Varela (diseño y fundición) y Antón Sánchez (policromía), 1551-1553. Capilla de las Doncellas, Catedral de Sevilla.

catedral sevillana. Se mandó pintar un zócalo hasta la altura de la reja lateral, el cual estaría subdividido en una parte baja, a modo de peana, una parte media de color pardillo y un friso superior donde "ha de echar unas letras como paresçiere a los señores". Se intuye por tanto, que debía correr por él una inscripción cuyo contenido no ha trascendido. Desde este friso, hasta la bóveda, el paramento iría decorado con motivos de grutescos, sobre color carmesí y entre ellos se intercalarían tres elementos precisos: las claves del arco de entrada debían ir doradas y sobre ellas, justo en el medio, se precisó la pintura de una jarra de azucenas, la cual iría flanqueada por dos escudos de armas del fundador, "como estan en el retablo con los colores que le conviniere de oro e plata".

Por otro lado, en las esquinas exteriores de la entrada, debían ir pintados dos pilares cuadrados, sobre los que apoyaría el friso antes referido, mientras que para la decoración de la cara interna de dicha puerta se eligen fingidas columnas abalaustradas. En el interior de este paso abovedado, el techo se pintaría de azul fino con estrellas de oro, "de buena forma que parezca çielo". Toda la obra debía ser realizada en aceite, a excepción del azul de esta bóveda celeste, y tendría que estar acabada para el día de Nuestra Señora, en agosto, fecha en la que intuyo que también debió instalarse definitivamente la reja.

Mientras que la policromía de la reja se conserva, aunque de forma sucinta, nada queda de esta decoración mural. Afinando la vista, hoy en día se aprecian los restos de un elemento ornamental distinto, el cual debe responder a una renovación decorativa posterior [Fig. 6]. Se aprecia la silueta de una estructura arquitectónica fingida que envuelve la entrada y se eleva hasta la mitad de la altura total. Recuerda a una suerte de arco triunfal rematado por un frontón recto decorado con 


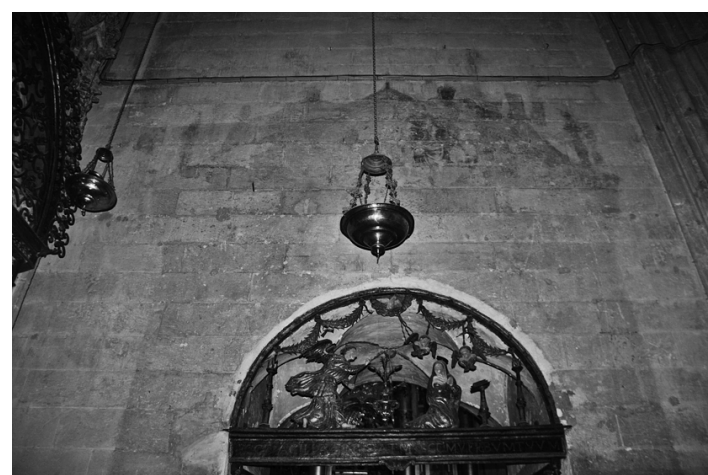

Fig. 6. Vista de la pared lateral externa. Capilla de las Doncellas, Catedral de Sevilla.

flameros. No existe información alusiva a ello, pues los autores que pudieron contemplarlo en épocas pasadas cuando aún el motivo fuera reconocible, como Ponz o Amador de los Ríos, no reparan en describirlo, quizá por la poca entidad estética del mismo o porque la situación esquinada en la que se encontraba lo llevaron a obviarlo. Sea como fuere, lo cierto es que en un primer momento la decoración de este paramento mural respondía a las corrientes estéticas del momento, siendo la elección del grutesco una consecuencia directa del conocimiento artístico que García de Gibraleón poseía de las novedades que ya triunfaban en Roma, donde el hallazgo de la Domus Aúrea de Nerón, hacia 1480, se convirtió en fuente de inspiración para los artistas del momento en su afán por recuperar la antigüedad clásica. ${ }^{12}$ Fueron muchos los pintores que se desplazaron hasta allí para copiar y estudiar el repertorio que se desplegaba ante sus ojos y fue gracias a esos dibujos que los motivos concretos de los grutescos empezaron a extenderse como la pólvora, apareciendo ya en cuadros o murales italianos de los años finales del siglo $\mathrm{XV}^{13}$ No obstante, se trataba de un recurso plástico ya empleado anteriormente en Sevilla, pues la decoración del cabildo civil contaba con un repertorio iconográfico que bien pudo servir de modelo al pintor Antón Sánchez. Se puede también considerar la idea de que hubiera podido tener acceso a la obra de Antonio de Salamanca, editor, tipógrafo y librero español establecido en Roma, quien, entre otras labores, se dedicó a la edición de estampas de vistas de la ciudad y de los hallazgos arqueológicos que contemporáneamente estaban teniendo lugar. Hacia 1500-1512, se encargó de dar a conocer las estampas que Nicoletto da Modena había realizado sobre la decoración del palacio de Nerón, basándose quizás no en el natural sino en los dibujos que el Pinturiccio había realizado de ellos. Asimismo, Diego de Sagredo, incluyó alusiones a este tipo de motivos en sus Medidas del Romano, tratado publicado hacia 1526 y que consiguió tener hasta cinco ediciones antes de 1556, por lo que no es de extrañar que circularan ejemplares por Sevilla en el momento en que se contrata la decoración exterior de la capilla. Referencias no le faltaron al pintor, que debió inundar la pared de motivos fantásticos, tanto engarzados en candelieri como de forma aislada donde cornucopias, panoplias, follajes, figuras humanas y tieromórficas, mascarones y seres mitológicos se desplegaban bajo las bóvedas de un templo cristiano. De este modo, la capilla se situaba a la vanguardia, exhibiendo primicias artísticas que, llegadas desde Italia, ya se habían convertido en imperantes en una ciudad por entonces acrisolada como puerto y puerta de América.

Al igual que ocurría con Antonio de Tejeda, la vida y obra de este pintor no ha sido atendida como merece pues, aunque es abundante la documentación de archivo que de él ha transcendido, no así su producción pictórica conservada. Se trata de un artista difícil de estudiar, dados los pintores homónimos que existieron en la Sevilla quinientista. Gestoso documenta hasta cuatro, desde el ocaso del siglo XV hasta el final del primer tercio de la centuria siguiente. ${ }^{14} \mathrm{El}$ análisis de los documentos encontrados, lleva a considerar a este Antón como hijo de Antón Sánchez de Guadalupe, quien participó seguramente en la decoración de los arcos triunfales que dieron la bienvenida al emperador el día que llegó a Sevilla en 1526 con motivo de su enlace con Isabel de Portugal, y quien estaba registrado como alcalde del gremio de pintores en esa misma fecha. Pertenecía, por tanto, a una familia de artistas pintores, pues su tío fue el afanado Pedro Fernández de Guadalupe, al cual se le atribuye el San Pedro, hoy en la Sacristía de los Cálices del templo metropolitano. ${ }^{15}$ Fue vecino de la collación del Salvador y a lo largo de su ca-

\footnotetext{
12 Para más información ver DACOS, Nicole, 1969.

13 FERNÁNDEZ ARENAS, José, 1979, pp. 5-20.

14 GESTOSO, José, 1909, pp. 390-393.

15 Resulta complicado el estudio de los Guadalupe en la Sevilla del siglo XVI, debido a la existencia de pintores homónimos y a las generaciones de artistas que se sucedieron dentro de la familia. No obstante, según los últimos datos, Antón Sánchez fue cuñado del pintor Antonio de Tejeda, quien casó con su hermana Juana. GÓMEZ SÁNCHEZ, Juan Antonio, 2016, p. 572.
} 
rrera profesional, se relacionó con lo más granado de la flor y nata artística de la Sevilla meso secular. No le debió resultar difícil entablar contacto y establecer fértiles relaciones con los pintores del momento, pues en 1552 figuraba como mayordomo del hospital y cofradía de los pintores, la cual tenía sede en la collación de San Martín, junto a la iglesia homónima. Así, en 1555, aparece como fiador del entallador Pedro Becerril en el contrato del retablo que éste se comprometió a hacer junto a Pedro de Campaña por encargo del mariscal Diego Caballero, destinado a la estancia situada junto al antecabildo de la Catedral sevillana. ${ }^{16}$

Debió ser cercana su relación con Becerril, pues en 1558, "ambos dos de mancomún" se obligaban a hacer un crucificado para la cofradía de las cinco llagas, la cual tenía sede en el convento de la Trinidad. Martín de Alcázar, mayordomo, y Juan de Azalón, cofrades, encargaron la obra, la cual debía ser realizada en madera de álamo blanco, teniendo ocho palmos y tres dedos de largo. El documento especifica "que sea muy de bulto y bien fecho y acabado ansi de talla como de pintura, a vista de maestros oficiales que de ello sepan, que vos daremos fecho y acabado según dicho es el domingo de ramos, pagándonos por la hechura $y$ el aparejo de madera 18 ducados de oro". ${ }^{17}$ Aunque en el contrato no se especifica, es de suponer que la obra estaba pensada para procesionar, dada la procedencia del encargo, así como la fecha estimada de entrega. Prácticamente todo entallador que se preciara en la Sevilla del siglo XVI tenía la hechura de algún crucificado a sus espaldas, ya fuera de madera o de pasta, desde Roque de Balduque hasta Marcos Cabrera, pasando por escultores afamados como Juan Bautista Vázquez, el viejo, o el veneciano Juan Marín. Por desgracia, son pocos los ejemplares de esta naturaleza que han superado el paso del tiempo, por lo que resulta complejo analizar la evolución formal y estética de los crucificados a lo largo de la centuria. No obstante, con esta referencia se evidencia el extraordinario beneficio que supuso para los talleres escultóricos y pictóricos de la ciudad la proliferación de nuevas hermandades y cofradías, pues requerían de titulares y retablos con los que dotar a sus capillas y hospitales.
En la década de los sesenta, participó en las labores de dorado y policromía del antiguo retablo mayor de la iglesia de San Lorenzo, hoy desaparecido y sustituido por uno barroco diseñado por Montañés y concluido por los hermanos Ribas. Diego de Ledesma, mayordomo de fábrica, estableció pacto y postura con Antón Sanchez, Andrés Ramírez, Antonio de Alfián y Pedro Villegas, a fin de otorgar una mayor entidad plástica a un retablo que se mantenía, por aquel entonces, en madera de lo blanco. ${ }^{18}$ Aunque no se conserva el documento contractual, sí un pago por el cual los citados pintores reciben 120 mil maravedíes, que suponen la mitad de la suma total por la que contrataron dichos trabajos. Se trata de una obra sufragada gracias al préstamo de 500 maravedíes que meses antes había realizado Gaspar de Cornieles, clérigo y mayordomo de la iglesia del Salvador, a petición de Lázaro Martínez de Cosar, mayordomo mayor de la fábrica de las iglesias del arzobispado. ${ }^{19}$ Fue, por tanto, una ayuda intereclesial la que permitió que se terminaran las obras de talla, dorado y policromado del referido retablo mayor de San Lorenzo, un hecho que da muestras de la extraordinaria capacidad de gestión monetaria y logística que se tenía dentro del Arzobispado en aquellos momentos.

Finalmente, y volviendo a la capilla de las Doncellas, es preciso señalar que mientras que la reja chica y la entrada lateral se encontrarían perfectamente terminadas a principio de los años sesenta, para ver completado el cierre férreo de la entrada principal de la capilla habrá que esperar hasta 1579. Se trata de una magna reja atribuida a Pedro Delgado, integrada por balaustres que siguen la morfología de los anteriormente descritos y rematada por una crestería cuya iconografía engarza con el cometido de la hermandad. En el centro aparece la imagen de la Virgen de la Caridad acogiendo bajo su manto a las doncellas, con una cartela a sus pies que la identifica. Sigue la iconografía de las vírgenes de misericordia, donde María, con gesto caritativo y misericordioso acoge bajo su manto a un grupo de figuras suplicantes que imploran a la Reina de los Cielos la salvación eterna. ${ }^{20}$ En los laterales dos cariátides sostienen un frontón curvo y roto con un candelabro en el cen-

\footnotetext{
${ }^{16}$ GÓMEZ SÁNCHEZ, Juan Antonio, 2016, p. 391.

17 Documento fechado el 8 de febrero de 1558. AHPSPN, oficio 23, legajo 16001, f. 424 y ss.

18 Documento fechado en 3 de febrero de 1561. AHPSPN, oficio 9, legajo 17558, ff. 457 y ss.

19 Documento fechado en 31 de enero de 1561. AHPSPN, oficio 9, legajo 17558, ff. 1413 y ss.

20 Existe una antigua, aunque completa, monografía sobre este tema iconográfico. PEDRIZET, Paul, 1908.
} 
tro, rematado por una cruz. En los extremos aparecen dos figuras de santos inscritas en cartelas, cuya falta de atributos dificulta su identificación. Gracias al resto de la decoración, compuesta por roleos vegetales, figuras humanas que brotan de tallos, ángeles y motivos florales, se genera un efecto visual de gran calidad plástica. Es de suponer que esta obra debía ir también policromada, pero no existen documentos que puedan aportar más información al respecto.

A pesar de ser una eminente estructura gótica, el devenir de los tiempos y la acogida de las nuevas corrientes estilísticas, llevaron a la catedral hispalense a convertirse en un auténtico contenedor de referencias renacentistas: desde la arquitectura de los nuevos espacios añadidos, como la Sacristía Mayor, la Sala Capitular o la Capilla Real, hasta la decoración de lugares como la Sala de Antecabildo o capillas como la de Scalas, o la de las Doncellas. Se convirtió en un verdadero escaparate para los artistas, quienes se pusieron al servicio del cabildo y de los distintos comitentes, intentando dar respuesta a sus voluntades siempre desde un buen quehacer, preciso y cuidado, pues su éxito en este tipo de obras supondría su ascenso dentro del gremio. Antonio de Tejeda y Antón Sánchez, aunque formados en la tradición, supieron interpretar lo que los nuevos tiempos requerían de ellos, interviniendo con garantías en un escaparate que se había convertido en punta de lanza, donde la evolución de las formas era un hecho y no un susurro, siendo las terracotas de Mercadante exégesis de un tiempo pretérito ya superado.

\section{Apéndice documental}

1. Archivo Histórico de la Provincia de Sevilla, Protocolos Notariales.

Oficio 1, legajo 46, registro 8 , sin foliar.

Sepan quantos esta carta vieren como yo Antonio de Texeda, pintor de ymagineria, vecino en la collación de Santa Maria Magdalena otorgo e conosco que hago pacto e postura con vos Garcia de Gibraleon, beneficiado de la iglesia de Santiago de la cibdad de Eçija que estades presente, en tal manera que yo sea thenido e obligado de pintar en la Capilla de las Doncellas que es en la Santa Iglesia de esta cibdad de Sevilla en la pared que esta frontero al altar mayor de la dicha capilla, hasta donde esta encalada la dicha pared, una historia del dia del juicio de buenas e finas colores e bien fecha e acabada a vista de maestros e de lo començar a hacer desde el dia que me dieredes fechos los andamios e de no alçar mado de ello fasta lo thener fecho e acabado so la pena que en esta carta sea contenida e vos el dicho beneficiado me deis por razon de lo suso dicho 20 mil maravedies de esta moneda que agora usa e dos cahices de trigo, en esta dicha cibdad de Sevilla, en paz e en salvo sin pleito e sin contienda alguno en esta manera los dichos 20 mil maravedíes, el primer tercio comenzada la dicha obra et el otro tercio mediada la dicha obra e el otro tercio restante en syendo acabada de haçer la dicha obra et los dichos dos cahices de trigo por el dia de Nuestra Señora Santa Maria del mes de agosto primero que viene de este presente año en que estamos de la fecha de esta carta pago en pos de otra so pena del doblo de cada pago con condiçion [tachado: que vos el dicho Garcia de Gibraleon] todo el oro que fuere menester para la dicha obra sea a costa de vos el dicho beneficiado Garcia de Gibraleon este en esta manera otorgo e prometo e me obligo de lo facer e cumplir asy e de non partir ni apartar de hacer lo suso dicho por mas ni por menos ni por tanto que [ilegible] de mi prometa ni por otra causa ni razon alguna qualquiera que sea e vos que me non podades dexar qualquier de nos cabsas las dichas partes que consta estos que dichos fueren e oviere e lo asy no pagare e tuviere que guardare e cumpliere e oviere por firme segund dicho es e pague e peche a la otra parte de nos obediende que por ello estuviere e lo viere por firme 5 mil maravedies de esta moneda que agora usa, por pena e por postura promisyon et solemne estipulacion conveniençia asosegada que hacemos e ponemos con todas las costas e mysiones e daños e menoscabos que la parte de nos obediente e otra pella hiciere et recibiere e si le reaçiere sobre esta dicha raçon et la dicha pena pagada o non pagada que este dicho pabto e postura e todo quanto esta dicha carta dize de cada cosa e parte de ello vala e sea firme en todo e por todo segund dicho es et yo el dicho beneficiado Garcia de Giblraleon que a todo esto dicho es presente soy otorgo e conosco que e recibido en esta dicho pabto e postura que vos el dicho Antonio de Texeda $m$ abeis fecho para hacer la dicha historia del dia del juicio por el dicho precio de los dichos 20 mil mrv e dos cahices de trigo con las dichas condiciones e penas e posturas e obligaciones et según dicho es otorgo e prometo e me obligo de pagar e thener que guardar e cumplir e aver por firme todo quanto esta carta dice e cada cosa de ello según dicho es so las penas de suso sontenidas [cláusulas notariales].

Fecha: 3 de enero de 1534

Firman: Antonio de Texeda y García de Gibraleon, además de los escribanos]

2. Archivo Histórico de la Provincia de Sevilla, Protocolos Notariales.

Oficio 16, legajo 9794, registro 6, f. 135 y siguientes.

Sepan quantos esta cartda de testamento vieren como yo Antonio de Texeda pintor de ymagineria, vecino que soy de esta cibdad de Sevilla en la collacion de Santa Maria Magdalena estando enfermo de cuerpo e sano de voluntad e en mi seso e acuerdo e 
entendimiento natural e en mi buena e cumplida memoria tal que Dios Nuestro Señor tuvo por bien de me dar teniendo firme e verdaderame la santísima trinidad padre hijo e espíritu santo otorgo e conozco que hago y ordeno dicho mi testamento en la manera e forma siguiente.

Primeramente mando e enconiendo mi anima a Dios Nuestro Señor [...] e que mi cuerpo sea sepultado en la iglesia de San Juan de esta dicha cibdad de Sevilla en la sepultura que ende me fuere dada en el dia de mi enterramiento estando mi cuerpo presente. Si fuere ora sino otro dia siguiente me digan una misa de réquiem cantada con su vegilia ofrendada del pan y el vino e cera que mis albaceas asi quisieren e nueve misas rezadas. Asi mismo ofrendadas del pan e vino e cera que mis albaceas quisieren e me acompañe la cofradía de la Concebçion, donde yo soy cofrade que es a los tres hospitales.

Yten mando que se digan seis misas rezadas por las animas de mis padre y madre en la dicha iglesia de San Juan e den por las deçir lo de costumbre.

Yten mando que digan otras seis misas rezadas por las anymas del purgatorio e que se digan en la dicha iglesia de San Juan e den por las decir lo que costase.

Yten mando se digan 4 misas rezadas por las personas a quienes yo encargo en la dicha iglesia de San Juan, e den por las decir lo de costumbre.

Yten mando que se digan las 33 misas de Santo Amador por mi anima e den por las decir lo que se acostumbre e se digan en la dicha iglesia de San Juan.

Yten mando que me digan las 13 misas de la luz en la dicha iglesia de San Juan y den por decirlas lo que es costumbre.

Yten mando a la obra de la iglesia de Sta Maria Magdalena donde yo soy perrochiano por reverencia de los Santos Sacramentos que de ella he recibido un real de plata e otro a la [ilegible] que se acompaña al santo sacramento de la dicha iglesia e a la cruzada e a las hordenes de la Santísima trinidad e a Santa Maria de la Merced para la ayuda de la redención de los cristianos que son cabtivos en tierra de moros e a San Lazaro e San Sebastian e,stramuros de Sevilla a cada una horden 5 maravedies e a Santa Maria de la Sede de Sevilla por sanar lo perdones que en ella son, 6 maravedies en dineros.

Yten declaro que las deudas que debo son las siguientes:

Yten declaro que devo dar a un mancebo que se dice ortega 10 ducados de oro de obras que ha fecho conmigo en el dicho nuestro oficio un retablo de un hombre de Huelva mando, que se lo pagasen de los dinero del dicho retablo que son 22 ducados los que se me deben de la dicha obra mando que los cobren y se los paguen.
Yten declaro que debo a Cebrian de Cariçate, mercader mi compadre, vecino en la collación de Santa Maria, un saco de azul que valdra hasta 6 ducados, mando que si quisiere recibir el azul que tengo que se lo vuelvan y le paguen lo que falta de ello de mis bienes.

Yten declaro que debo a Andres Morin pintor, vecino en la collacion de Santa Maria, a la borzeguineria, 3250 maravedies de cierta obra que me fizo e mando que se lo pague de mis bienes.

Yten declaro que las debdas que a mi me deben son las siguientes:

Yten declaro que me debe Alonso Perez, pintor vecino en la collacion de San Martin, 2 ducados de oro en préstamo que le preste, mando que los cobren de el.

Yten declaro que yo tengo resçibidos de la mujer de Jorge Fernandez 3 ducados de oro para en quenta de un retablo que le fago por 10 ducados, mando que acaben el dicho retablo e cobren los otros 7 ducados que me deben.

Yten declaro que yo tengo cargo de façer un retablo del almirante e tengo recibidos 8 mil maravedies para en quenta de los 24 mil maravedies que valen. Lo tengo fecho hasta los dichos 8 mil maravedies, mande se acabe dicho retablo e cobren los maravedies restantes.

Yten declaro que yo tengo fecho un retablo para el lugar de la Campana y tengo recibidos para en quenta del lo que paresçiere por mis conocimientos, por ende mando que Francisco de Texeda mi hermano, lo acabe e cobre en lo que restare del dicho retablo y [ilegible] con ello a mi mujer y herederos.

Yten declaro que yo tengo acabada una viga de pintura de la iglesia de San Salvador de esta cibdad y tengo recibido 26 mil maravedíes, mando que se acabe un poco que queda de ella y cobren de la dicha fabrica los maravedíes que me restaren, debiendo de ella lo que juzgaren maestros pintores de imagineria.

Yten declaro que yo tengo fecho un retablo para la iglesia de la villa de Palos por presçio de 84 mil maravedies y tengo recibidos ciertos maravedies para en cuenta de ellos, según paresçio por mi conoscimiento, mando que se acabe el dicho retablo e cobren el resto de lo que me devieren para mis herederos.

Yten declaro que yo tengo en dineros hasta 60 ducados de oro en poder de Juana Sanchez, mi mujer que esta presente, e yo la dicha Juan Sanchez siendo presente confieso e declaro que tengo en mi poder los dichos 60 ducados de oro.

Yten yo el dicho Antonio de Texeda da testador a Francisco de Texeda mi hermano, 10 ducados de oro porque ruegue a Dios por mi anima. 
Yten mando a Jorge mi criado 2 ducados de oro para una capa por descargo de mi conciencia e porque ruegue a Dios por mi anima.

Yten a Antonio mi criado otros 2 ducados de oro por descargo de mi conciencia e por que ruegue a Dios por mi anima.

Yten declaro que debo a Ortega, entallador vecino en la collacion de Santa Maria, un cahiz de trigo que me pesto en trigo para pagar lo nuevo de este presente año, mando que se lo paguen de mis bienes.

Yten declaro que debo a Fernando Altamirano, mi tio, medio cahiz de trigo que me presto, mando que se lo paguen de mis bienes en trigo.

Yten declaro que al tiempo e sazon que yo case con la dicha Juana Sanchez, mi mujer, resçibi de ella en dote e casamiento 5 mil maravedies en ropas de su persona e casa, mando que sea ante todas cosas pagadas y entregadas de ello e que al tiempo que yo case con ella no tenia bienes algunos e que lo bienes que hoy dia tenemos son multiplicados durante, entre mi y ella en el matrimonio. Mando que la dicha mi mujer sea pagada e entregada de la mitad de los dichos bienes que hoy dia tenemos por cuanto le pertenesçen de derecho.

Pagado e cumplido este mi testameto e todo lo en el contenido de mis bienes según que aquí esta escripto e ordenado todo lo que al fin hare e remanesciere de los dichos mis bienes ansi muebles como de rayces mando que los ayan e los hereden todos Nicolas e Leonor e Juan, mis hijos legitimos e de la dicha Juana Sanchez, mi mujer, e los cuales dejo e instituyo por legitimos e universales herederos en el remaniente de los dichos mis bienes muebles y rayces.

Para pagar e cumplir este dicho mi testamento e todo lo en el contenido de mis bienes según que aquí esta escripto e ordenado dejo e establezco por mis albaceas a la dicha Juana Sanchez, mi mujer e a Fernando Altamirano, mi tio, vecino en la collacion de San Juan, a los quales doy y otorgo libre e llereno e cumplido poder para que ellos e cada uno de ellos o quien su poder de ellos o de qualquiera de ellos oviere pueda entrar e tomar e vender e rematar a tantos de los dichos mis bienes ansi de muebles como de rayces que tanto cumplan e basten para los pagar e cumplir en que en ellos se fiçieren por mi anima.

Por esta carta de mi testamento revoco e anulo e doy por ningun e de ningún efeto e valor todos e quealesquier testamentos e mandas e codicilos que yo haya otorgado ansi escriptos como por palabras desde todos los tiempos pasados fasta hoy dia de la fecha de esta carta [cláusulas notariales].

En Sevilla en las casas de la morada del dicho Fernando Altamirano que son en la dicha collacion de San Juan.

Fecha: 7 de julio de 1536

Firma: Antonio de Texeda
3. Archivo Histórico de la Provincia de Sevilla, Protocolos Notariales.

Oficio 16, legajo 9836, folio 159 y siguientes.

Sepan quantos esta carta vieren como yo Anton Sanchez, pintor, vecino que soy en esta cibdad de Sevilla en la collacion de San Salvador otorgo e conozco que soy convenido e concertado con vos los señores priores conçiliarios de la capilla de las doncellas e con el arcediano de Ribadesil y con el licenciado Gonzalo Suarez de Leon, priores de la dicha capilla en su nombre, que estan presentes en esta manera que yo me obligo de dorar e pintar una reja que esta en la dicha capilla de las Doncellas en la puerta chica según e como es que fue rematada en mi con las condiciones e obra que en ella se a de facer como se contiene en una memoria que su tenor dice en esta siguiente.

\section{[Condiciones]}

Muy magnificos señores las condiciones que vuestras mercedes me mandaron hacer para dorar e pintar esta reja de esta capilla son las siguientes.

Primeramente es condicion que el mestro que esta obra tomare la ha de empezar con su emprimadura al olio todo aquello que esta viere por estañar e despues de ympimado asi de dorar e pintar de esta manera.

Primeramente la imagen de nuestra señora ha de ir dorada de [ilegible] y el manto ase de pintar sobre el oro unas purpuras senbradas por el de azul echandole su açinefa por la orilla labrada de una lavor e en la saya ha de facer un brocado de carmin sobre el oro los cabellos e diadema han de ir dorados.

Yten el angel he de ser todo dorado por ambas partes y en el alba ha de sembrar unas purpuras de un color que levante aguardandole su orilla y en el almatica a de pintar un brocado de verde echandole una çenefa por la orilla de una labor y en la capa otro brocado labrado de carmin aguardandole sus orillas, dorandole los cabellos y diadema y el çetro e retulo y en el retablo de pintar unas letras que diga ave maria despues despues de esto han de [ilegible] cada festa e ropas con las colores que les convenga a cada ropa porque [ilegible] una de otra e los rostros e mantos muy bien encarnados e pulidos abriendoles ojos e bocas que es conforme a buenas obras.

Yten la jarra y açuçenas han de ir doradas y las hojas y las hojas de las azucenas han de ir rascadas de verde y ansi mismo en las flores matizandolas de carmin sobre el oro.

Yten el atril con el libro y los cantos de las hojas ha de ir todo dorado y las hojas dado de blanco y escripto en ellas unas letras.

Yten los candeleros que estan en los lados han de ir todos dorados por ambas partes e los fuegos de carmín. 
Yten la nube donde esta el espiritu santo ha de ir dorada y la paloma ha de ir de blanco por que parezca.

Yten el arco que corre por encima de esta obra por entre ambas partes con el papo y las rosas que estan en el sembradas ha de ir todo dorado y las rosas rascadas de verde y de carmín.

Yten cuatro festones que salen del arco han de ir dorados por ambas partes y las hojas resacadas de verde e los frutos de carmin por que parezca cada rosa.

Yten un friso que corre del ancho de la reja ha de ser de esta manera que la moldura alta por ambas partes han de ser doradas e pintadas por ella una follesta perfilada de prieto y los campos de color porque le [ilegible] cada rosa.

Yten otra moldura que viene por lo bajo ha de ir dorada y en el llano que esta entre las molduras ha de ir todo dorado de ambas partes y ha de llevar un letrero azul de la nota que vuestras mercedes mandaron poner.

Yten las puertas de esta rexa que son balaustres y entorchados que tienen unos nudos por alto e por baxo e por medio e han de ser dorado a la redonda e ansi mismo el papo de las puertas ha de ir dorado con el maço e cerradura de ambas partes.

Yten toda esta rexa he de ir muy bien sacada de orofino e de buen lustre ansy por una parte como por la otra e ha de ir muy bien pintada con muy buenos colores ansi ropas como rostros e todo lo demas como conviene a buena obra a vista de oficiales.

Yten el angel de esta historia, las alas han de ir doradas por ambas partes e han de ser sacadas de carmin o de verde las plumas que salgan unas de otras.

Yten el papo del friso ha de ir todo dorado y el batado de las puertas.

Yten dos niños o serafines que se han de poner sobre la imagen de nuestra señora han de ser doradas las alas y cabellos por ambas partes sacadas las alas de carmin o verde de manera de plumas e los rostros bien encarnados conforme a las figuras.

Yten es condicion que el maestro que esta obra tomare se ha de obligar a pagar al maestro que hizo las dichas condiciones un ducado e a los maestros que se juntaren al remate otro ducado e ha de obligarse a pagar al escribano e ha de obligarse a dar fyança abonada es a contento de sus mercedes e si alguna cosa de menos quedare por poner en estas condiçiones que sea necesaria a la dicha obra que sea obligadolo se facer sin pedir otra demasia ni alegar otro derecho niguno.

E yo Anton Sanchez maestro de las dichas condiciones digo que los hice e firme de mi nombre e puse de primera por esta postura la dicha obra en 15 mil maravedíes con condicion que yo quedare e sea obli- gado a poner el oro e las colores que faren menester e todos los otros aparejos e andamios, se le paga la mitad luego e la otra mitad acabada la dicha obra corregida e visitada que este conforme a buena obra e que luego la comiença e no alçar mano de ella hasta que la acabe e que si alçare mano que tome maestros que la acaben sin otra prueba ni diliegncia alguna e le pueda executar por los 9 ducados que luego reçibe e por lo mismo que costare.

En Sevilla en la capilla de las doncellas, en jueves 22 dias del mes de mayo del año de nuestro salvador lesuchristo de 1553. Los señores arcedianos Ribadesil canonigo en la santa iglesia de Sevilla y el licenciado Gonzalo Suarez de Leon priores de la dicha capilla de las Doncellas mandaron que se ha de facer esta obra al pintor que por menos precio la hiciere, ansy habiendo leido las dichas condiciones e obra de suso declaras y estando presente ciertos oficiales de pintores hubo para ello las posturas siguientes.

Alonso de Solis, pintor vecino a San Pedro la puso en 14 mil.

Andres de Zamora, vecino a la arandela, la puso en $13 \mathrm{ml}$.

Francisco de Esquivel, vecino de Santa Maria, la puso en 12 mil.

Andres de Zamora la puso en [sin completar]

El dicho Francisco de Esquivel la puso en 26 ducados. Alonso de Solis la puso en [sin completar]. Andres de Zamora las puso en 20 ducados. Pedro de Campos la puso en 19 ducados.

Anton Sanchez, vecino al salvador, la puso en $18 \mathrm{du}$ cados.

Porque no hubo persona que por menos precio de obligare a facer la dicha obra que vos, el dicho Anton Sanchez para que la haga conforme a las dichas condiciones. Testigos Miguel Geronimo de Leon y Anton Perez, escribanos de Sevilla.

LO qual dicha obra otorgo e prometo e me obligo de no alçar mano de ella hasta no aberla acabado en toda perfecion e contí de 18 ducados para en quenta de los quale she reçibido 9 ducados en reales de plata en presencia del señor escribano publico e testigos yuso escriptos los quales reçibi del benefiçiado Hernando Suares estante en la dicha capilla e que son en mi poder de que soy y me otorgo por vos por bien contento e pagado e entregado a toda mi voluntad [clausulas] y los otro 9 ducados restantes me los habéis de dar e pagar acabada que este la dicha obra conforme como se contiene en las condiciones se suso encorporadas e me oblifo desto tener e guardar e cumplir so las penas contenidas y en esta manera otorgo e conozco que me obligo de no yr ni venir contra ellas [clausulas] voy doy conmigo como mi fiador a Pedro Villegas, pintor, vecino de la cibdad de Sevilla en la collacion de San Martin que estades presente [claúsulas notariales].

Fecha: 24 mayo 1553

Firman: Antón Sánchez y Pedro Villegas. 
4. Archivo Histórico de la Provincia de Sevilla, Protocolos Notariales.

Oficio 16 , legajo 9836 , folio $619 v^{\circ}$ y siguientes

Sepan quantos esta carta vieren como yo Anton Sanchez pintor soy convenido e concertado con los señores priores de la capilla de las doncellas [roto e ilegible] que yo me obligo de facer la obra de pintura de la dicha capilla según e conforme sera declarado y según las dichas condiciones que de ello se ha leido y que son las siguientes:

Memorial de las condiciones con que se ha de pintar la portada de la capilla de las doncellas a donde se puso la rexa nueva la cual mandaron hacer los magestuosos priores e conçiliares de la dicha capilla.

Primeramente es condicion que la boveda del arco de la puerta que todas las claves sean doradas de una cinta de ancho de tres dedos que se entiende las esquinas y ansy mismo la cinta del arco de la capilla que es la esquina ha de llevar la cinta como las otras y la esquina que junta con la rexa, ansi mesmo las bovedas que juntaron con la pared todas han de llevar la cinta que arriba esta dicha.

Yten todos los llanos d ella bovedas han de ser metidos de azul fino de dos manos que quede bien cubierto y encima unas estrellas de oro e de buena forma que parezca cielo y un hierro que esta en medio de esta boveda ha de ir dorado a la redonda del a de llevar una filetera de oro de ancho de un palmo de todas partes.

Yten por los lados de la pared an de ser pintadas de esta manera un friso que corre por la reja dorada que corre con su [ilegible] por entrambos lados de la pared para que sea todo una cosa e ha de ser pintado de un pardillo que tenga buen color por el dicho friso ha de echar unas letras como paresciere a los señores y de este friso hasta las bovedas altas ha de ir pintado un brutesco y de colores sobre un colorado muy fino asi de la una parte como de la otra.

Yten las descendidas de abaxo del dicho friso ha de hacer una manera de pared conforme a la color del friso echandole sus costados de claro y esquiro y a de sentar esta pared sobre una peana de moldura que junte con el suelo de la capilla y en el medio de la dicha pared asi de la una parte como de la otra ha de ser de una piedra de jaspe y las esquinas que salen por dentro de la capilla ha de pintar dos columnas abalaustras e por junto a la reja dos pilares quadrados que reciban el friso y carguen sobre la peana baja y esto ha de ser pintado de aceite excepto el azul de las bóvedas.

Yten se ha de pintar la portada por parte de fuera de esta manera, primeramente en la canteria de los lados de la reja a de tomar media vara de cada parte y ha de ir subido en cuadrado hasta la segunda hilada que esta encima de la cinta azul esto ha de ir pintado de esta manera que todo este campo se ha de pintar de jaspe de colores y las cintas de la mezcla ha de ir dorados de oro mate echandole por los lados las mismas cintas de oro porque haga cuadrado y en medio de la pintura encima de la rexa ha de pintar una jarra de nuestra señora con sus azucenas doradas y a los lados de las esquinas dos escudos con las armas del fundador de la capilla como estan en el retablo con las colores que le conviniere de oro e plata y este jaspe de fuera ha de ir al temple.

Yten que el oficial que esta obra tomare ha de poner el oro y las colores y el aparejo exepto el andamio que lo ha de poner la capilla y que esta a su costa.

Yten que el oficial en que se rematare sea obligado de pagar a el escribano y pregonero e tambien sea obligado de pagar por las condiciones a los oficiales que se hallaren presentes al remate y demas de esto sea obligado de pagar al maestro que hizo la muestra o debuxo de esta obra e que si no lo rematare de presente que sea la capilla obligada a pagar las dichas condiciones e debuxo.

Yten es condicion que esta obra se ha de acabar dentro de 15 dias primeros siguientes dende la obligacion y ha de ir muy bien fecha con muy finos colores y buen oro a parecer de oficiales.

Yten que ha de acabar esta obra del todo para el dia de Nuestra Señora de agosto so pena de lo hazer a su costa con otros oficiales.

Yten es condiçion que por lo que se rematare se le diera la mitad y luego la otra mitad acabada la obra.

Yten es condicion que sea dexo por vista de oficiales y pueda dar por fiador a que lo acabara conforme a buena obra.

En la muy noble e leal cibdad de sevilla 2 dias del mes de julio de 1553, estando en la capilla de las Doncellas de la advocacion de la Anunciacion de Nuestra Señora estando presente el arcediano Ribadesil canonigo y el licenciado Geronimo Suarez de Leon priores y el maestre escuela el dotor Martin Gasco canomigo y Diego de Ribera clerigo y Diego Hernandez de la torre conciliarios y Anton Manuel, tesorero y el beneficiado Hernan Suarez, secretario de la dicha capilla dijeronque la dicha obra en estas condiciones se ha de rematar luego en el pintor que en mas bajo precio se ofresciere de facer e asi estando presentes ciertos pintores por el dicho secretario Hernan Suarez fueron leidas las dichas condiciones en presencia de los testigos yuso escriptos, fueron fechas las posturas.

Puso la obra Diego Sanchez en 40 ducados. Pusola Diego de Campos en 14 mil maravedies. Andres Ramirez la puso en 13 mil maravedies. Andres Morillo la puso en 12 mil maravedies. Anton Sanchez la puso en 12 mil maravedies. Pedro de Campos la puso en 15240 maravedies. Antonio de Arteaga, en 11200 maravedies. Andres Ramires, en 10320 maravedies. 
Anton Sanchez, en10 mil maravedies.

Pedro de Campos en 9750 maravedies.

Anton de Arteaga en 9370 maravedies.

El dicho Anton Sanchez, en 9 mil maravedies.

Luego fue dicho por los dichos señores priores e consiliarios dixeron que el pusiese la dicha obra en ocho mil maravedíes que se le rematase y quedase en el nombre de quin la pusiere para que la haga e asi el dicho Anton Sanchez, puso la dicha obra en los dichos ocho mil maravedíes [...]

Otorgo e prometo que me obligo de la manera suso dicha de façer e de cumplir la dicha obra e de luego poner mano en ella de no la dejar e dar fasta acabada conforme a buena vista de maestros pintores guardando las condiciones de la dicha obra de suso encorporadas e me doy por pagado de la mytad de que tengo reçibidos e de que coy contento a mi voluntad e los otros cuatro mil maravedíes restantes me los deys acabada la dicha obra so pena del doblo [cláusulas] para que asy cumpliré pongo por mi fiador y principal pagador a Antonio de Arteaga [es una confusión del escribano, pues la firma es de Antonio de Alfian], pintor de ymagineria vecino de Sevilla en la collación de la Magdalena [clausulas notariales].

Fecha: 2 julio 1553

Firman: Antonio de Alfián y Antón Sanchez

\section{Bibliografía}

FERNÁNDEZ ARENAS, José. "La decoración grutesca. Análisis de una forma", D'Art: Revista del Departament d'Historia de l'Arte, 1979, núm. 5. Barcelona: Universidad de Barcelona, pp. 5-20.

DACOS, Nicole. La découverte de la Domus Aurea et la formation des grotesques à la Renaissance. Leiden: Warburg Institut, 1969.
GESTOSO, José. "Cristóbal de Morales, pintor sevillano". Revista de Archivos, Bibliotecas y Museos, 1900, tomo IV. Madrid, pp. 386-390.

GESTOSO, José. Ensayo de un diccionario de los artífices que florecieron en Sevilla desde el siglo XIII al XVIII inclusive, t. III. Sevilla: La Andalucía Moderna, 1909.

GIL, Juan. Los conversos y la inquisición sevillana, vol. II. Sevilla: Universidad de Sevilla, 2000.

GÓMEZ SÁNCHEZ, Juan Antonio. Alejo Fernández y la pintura sevillana del primer tercio del siglo XVI [Tesis doctoral, no publicada y parcialmente consultable]. Sevilla: Universidad de Sevilla, 2016.

HERNÁNDEZ DÍAZ, José. Documentos para la Historia del Arte en Andalucía: Arte y artistas del Renacimiento en Sevilla, t. VI. Sevilla: Universidad de Sevilla, 1933.

OLLERO PINA, Juan Antonio. "Micer García de Gibraleón († 1534), un bróker eclesiástico en la Roma del Renacimiento". Hispania, 2016, vol. LXXVI, nº. 253. Madrid: CSIC, pp. 355-384.

ORTIZ DE ZÚÑIGA, Diego. Anales eclesiásticos y seculares de la Muy Noble y Muy Leal ciudad de Sevilla. Madrid: Imprenta Real, 1677.

PEDRIZET, Paul. La Vièrge de Miséricorde. Étude d'un thème iconographique. Paris: Ancienne Libraire Thorin et Fils, 1908.

POST, Chandler R. A History of Spanish Painting. The early Renaissance in Andalusia, vol. X. Cambridge: Harvard University Press, 1950.

RÍOS COLLANTES DE TERÁN, Inmaculada. "Noticias sobre la reja de la Capilla de las Doncellas". Archivo Hispalense, 2013, tomo XCVI, núms. 291-293. Sevilla: Diputación de Sevilla, pp. 415-440.

SERRERA CONTRERAS, Juan Miguel. "Pintura y pintores del siglo XVI en la Catedral de Sevilla". En: ANGULO ÍNNIGUEZ, Diego (coord.). La catedral de Sevilla. SeviIla: Ediciones Guadalquivir, 1984, pp. 353-404.

VALDIVIESO, Enrique. Historia de la pintura sevillana. Sevilla: Ediciones Guadalquivir, 2002. 
